\title{
O IMAGINÁRIO MÍTICO EM NARRATIVAS ORAIS AMAZÔNIDAS
}

\section{THE MYTHICAL IMAGINARY IN AMAZONIAN ORAL NARRATIVES}

\author{
Mariléia da Silveira Nobre¹, Fátima Pessoa²
}

\begin{abstract}
RESUMO: Este artigo visa compreender, pelas práticas discursivas de agricultores da Vila de Caraparu, a constituição e o funcionamento do imaginário que se projeta no real sócio-histórico em que vivem, como parte constitutiva de suas condições de existência material. Há, portanto, neste texto, um gesto de compreensão que busca reconhecer as regularidades de uma formação discursiva e ideológica que sustenta a crença nas regras que regem o cotidiano desses sujeitos e impõe a obediência a elas. Para o alcance desses objetivos, articulam-se as abordagens etnográfica e discursiva na análise de narrativas dos agricultores e das agricultoras mais antigos/antigas da região. Defende-se, como resultado do percurso de análise, o reconhecimento de uma formação discursiva mítico/cabocla, que rege a relação entre seres humanos e não-humanos pautada no temor e no respeito pelos seres não-humanos e na reciprocidade entre eles.
\end{abstract}

PALAVRAS-CHAVES: imaginário; formação discursiva; Amazônia; encantaria

ABSTRACT: This article aims to understand, through the discursive practices of farmers in Caraparu Village, the constitution and functioning of the imaginary that is projected in the socio-historical real in which they live, as a constituent part of their material conditions of existence. Therefore, there is, in this study, a gesture of understanding that seeks to recognize the regularities of an ideological and discursive formation that supports the belief in the rules that govern the daily lives of these subjects and imposes obedience to them. To achieve these goals, the ethnographic and discursive approaches are articulated in the analysis of narratives by the oldest farmers in that region. It is advocated, as a result of the analysis, the recognition of a mythical / caboclo discursive formation, which governs the relationship between human and non-human beings based on fear and respect for non-human beings and based on the reciprocity between them.

KEYWORDS: imaginary; discursive formation; Amazon; enchantment

\section{Introdução}

Na vila de Caraparu, localizada no nordeste da Amazônia paraense ${ }^{3}$, estabeleceu-se uma comunidade de agricultores cujo real sócio-histórico constitui-se pela crença em entidades

\footnotetext{
1. Doutoranda do PPG em Antropologia e Sociologia da UFPA. Bolsista CAPES

${ }^{2}$ Docente do PPG em Letras da UFPA. Doutora em Estudos Linguísticos pela UFMG.

${ }^{3}$ A vila de Caraparu fica a 15 minutos da sede do município de Santa Izabel do Pará. O acesso se faz pela rodovia PA-140 ou, para quem prefere se deslocar de Belém até a vila por via fluvial, o percurso é feito pelo rio Guamá (um dos afluentes do rio Amazonas) e deste até o rio Caraparu.
} 
sobrenaturais que interferem no cotidiano do trabalho daquela população. A origem das comunidades lá estabelecidas está estreitamente vinculada ao processo de distribuição do quilombo do Caxiú nas cabeceiras do rio Capim. Essa população se organizou em forma de "mocambos" a partir do segundo quartel do século XIX e deu origem à maioria das localidades do distrito, conforme documento histórico da Prefeitura Municipal de Santa Izabel do Pará, citado por Nobre (2007). Após 15 anos de pesquisas etnográficas realizadas naquela comunidade $^{4}$, tornou-se imperativo investigar os processos por meio dos quais a crença nessas entidades sobrenaturais se consolidou e os processos por meio dos quais essa crença se mantém ou se transforma entre os sujeitos dessa comunidade.

Considerando-se a natureza desta investigação, foi necessário visitar um campo teórico exógeno ao da Antropologia, qual seja, o campo da Análise de Discurso Materialista. Foram evocados deste campo os conceitos de real, de imaginário e de simbólico, entrelaçados na releitura que Michel Pêcheux (1975) faz dos trabalhos de Jean Jacques Lacan e de Louis Althusser. Com base nesse referencial teórico, busca-se compreender o funcionamento do imaginário materializado em práticas discursivas sobre o cotidiano da vida e do trabalho em Caraparu, por meio da escuta de narrativas dos agricultores e das agricultoras ${ }^{5}$ mais antigos/antigas da região. Há, portanto, nesta pesquisa, um gesto interpretativo que busca reconhecer as regularidades de uma formação discursiva e ideológica que sustenta a crença nas regras que regem o cotidiano desses sujeitos e impõe a obediência a elas.

Nessa perspectiva, além das noções de real, imaginário e simbólico já pontuadas, a noção de ideologia em Pêcheux (1975) se mostrou pertinente para essa investigação. Faz-se referência a este conceito com base em postulados de Althusser (1970, p.79), ao afirmar que a ideologia é "uma representação da relação imaginária dos indivíduos com suas condições reais de existência". Orlandi (2012) também contribui para a apropriação desse conceito, ao dizer que a ideologia não é vista como conjunto de representações, como visão de mundo ou como ocultação da realidade. Para a autora, "não há realidade sem ideologia" (ORLANDI, 2012, p. 48). O sujeito vivencia projeções imaginárias em um contexto cultural específico. Entende-se, então, que a maneira de enxergar o real é sempre da ordem do imaginário.

\footnotetext{
${ }^{4}$ São pesquisas realizadas no percurso de minha formação acadêmica na graduação (NOBRE, 2004), no mestrado (NOBRE, 2007) e atualmente no curso de doutorado.

${ }^{5}$ Os colaboradores da pesquisa são membros das famílias de agricultores tradicionais, pertencentes ao Distrito de CaraparuPA, que trabalham com a produção de subsistência da farinha de mandioca, ofício passado de geração a geração. 
Com base em postulados teóricos próprios a uma abordagem etnográfica e discursiva, desenvolvidos na seção seguinte, propõe-se a discussão dos recortes de narrativas na construção dos gestos de interpretação que sustentam a defesa de uma formação discursiva mítica/cabloca que rege a relação entre seres humanos e não-humanos pautada no temor e no respeito pelos seres não-humanos e na reciprocidade entre eles.

\section{Os processos discursivos constituintes do mundo mítico de Caraparu}

Dornelles (1999) destaca que a linguagem é organizada como um sistema onde o imaginário, pela representação, tenta dar sentido ao que escapa do simbólico. O real, por sua vez, consiste no todo que não se pode apreender por meio da linguagem, mas, mesmo abstrato, a constitui: “o real é o impossível de dizer, impossível não dizer” (MILNER, 1987 apud DORNELLES, 1999, p.155). O imaginário projeta-se sobre o real, que é impossível de ser significado em seu todo/impossível de não ser significado. Fernandes (2008) destaca que o real, sendo o impossível de não dizer de uma determinada maneira, representa o modo como o sujeito é capturado pela ideologia. Isso significa dizer, segundo essa autora, que o sujeito acredita que a única forma possível de formulação é aquela que ele produziu, descartando qualquer outra possibilidade por um princípio de seleção essencialmente ideológico.

O real sócio-histórico, como destaca Dornelles (1999), é da ordem dos processos sociais, das práticas sociais que têm como agente constituinte/constituído o sujeito. A estrutura acolhe o sujeito ideológico no seu interior, pois "a realidade estruturada é efeito das relações imaginárias (ordem do inconsciente e do ideológico) pelas quais o sujeito faz um corte nesse real e produz a sua realidade, onde parte desse real é excluída, e deixada para fora como um todo que não cessará de se apresentar na simbolização dos processos sociohistóricos" (DORNELLES, 1999, p.157). No entanto, como lembra Fernandes (2008), essa materialidade, assim como a língua, não é acessível no seu todo. Ou seja, o sujeito produz uma simbolização desse real intangível de modo que este se torne, pelo menos ilusoriamente, representável. É, dessa maneira, no trabalho da linguagem que a ideologia surge, filiando o sujeito a um sítio de sentidos construídos historicamente.

Para representar o real, discursivizá-lo, é imprescindível que se passe pelo imaginário. O imaginário seria o recorte feito no real, ou seja, uma parte resultante desse recorte, por se "tratar de uma ilusão necessária à existência da discursividade" (SERRANI, 1993 apud FERNANDES, 2008, p. 41). Então, a relação do sujeito com a realidade é imaginária, a produção dessa realidade é puro efeito ideológico. 
O sujeito interpreta o real segundo sua interpelação ideológica de acordo com a formação discursiva na qual se inscreve por tradição, construindo o que Fernandes (2008) destaca como diversas realidades, todas direcionadas para um mesmo acontecimento histórico. Em Caraparu, as diversas realidades que se busca compreender estão relacionadas à crença em seres sobrenaturais e às práticas discursivas dos colonos em torno de suas entidades míticas. A formação discursiva que se busca reconhecer é aquela que sustenta a crença no mundo mítico de Caraparu e nas regras que, nesse mundo mítico, se constituem para reger o cotidiano desses sujeitos, impondo obediência a elas.

Nas concepções locais, os termos "bichos do fundo" e "bichos da mata" fazem referência, respectivamente, às entidades sagradas que habitam o fundo do rio Caraparu, afluente do rio Amazonas, e as matas da região. Vale ressaltar que este rio foi, por muito tempo, para os moradores da região, o único meio de acesso a Belém, capital do estado do Pará. Para os moradores locais, o rio Caraparu e as matas da região são espaços considerados sagrados, onde vivem, respectivamente, o boto, a oiara, o curupira. Esses lugares são denominados de "encante", a morada dos encantados, denominados pelos moradores locais de "bichos". O encante é um lugar considerado sagrado, pois é um espaço onde sempre se deve "pedir licença" para adentrar. O rio e a mata são espaços onde os moradores respeitam e temem qualquer mal vindo dos encantados.

Esses espaços fazem parte da dinâmica econômica e social do colono desde sua chegada nessa região. Em suas narrativas, o sujeito discursivo os representa como um lugar sagrado, pertencente aos encantados do fundo e da mata. Na relação que se constitui entre os colonos e os seres míticos, enraizadas nos espaços de trabalho do agricultor e da agricultora, marca-se uma relação hierárquica entre aqueles a quem pertence o lugar, os encantados, e aqueles que estão autorizados a frequentá-los, os colonos, desde que obedientes às regras que regem o cotidiano do trabalho e do lazer.

Descola (1994) afirma que, nas relações entre humanos e não-humanos, formata-se uma simbiose em que a pessoa é parte do meio ambiente e o meio ambiente é parte da pessoa. Corroborando com essa posição, Wawzyniak (2012) enfatiza que a dimensão social entre humanos e não-humanos, no caso específico de sua pesquisa relativa à cosmologia e ao cotidiano de ribeirinhos do Rio Tapajós, são fornecidos pelo sistema cultural que não estabelece dicotomia ou antagonismo entre as dimensões natural, cultural e sobrenatural. Para esse autor, esse mundo é um universo transformacional, povoado por uma pluralidade de agentes humanos e não-humanos. Essa realidade representada por Wawzyniak (2012) converge com a realidade representada nos dados etnográficos e discursivos levantados na Vila de Caraparu. Nessa 
discussão, postula-se, então, que os princípios que orientam essa relação entre humanos e nãohumanos são constituídos por um imaginário que fundamenta a crença nas regras que regem o cotidiano dos colonos em Caraparu.

Com relação à sacralidade desses espaços, retoma-se Eliade (2001), quando destaca que na dinâmica da religiosidade o espaço sagrado ocupa um lugar fundamental, pois é o lugar da manifestação da divindade. No contexto amazônico, as práticas e os ritos do catolicismo popular mais a diversidade religiosa indígena, com seus mitos e crenças, segundo Maués (2005), desaguam, na cultura cabocla amazônida, uma grande riqueza de mitos, crenças e práticas no que diz respeito à diversidade cultural de suas populações. Eliade (2002) destaca que os mitos não são vistos como fábulas ou ficções pura e simplesmente, mas como realidade. O mito, afirma Eliade (2002, p.12), “é considerado uma história sagrada e, portanto, uma história verdadeira, porque sempre se refere a realidades (...) o mito se torna o modelo exemplar de todas as atividades humanas significativas". Para Câmara Cascudo (2012), os mitos brasileiros vêm de três fontes essenciais: a cultura portuguesa, a cultura indígena e a cultura africana. No entanto, o autor destaca que o elemento branco colonial foi o responsável pela maioria dos mitos, senão em volume, mas em força modificadora em ação contínua. Nenhum mito se imunizou do prodígio contato e todos trazem vestígios, decisivos ou acidentais, sempre vivos, do "efeito" português.

No entender de Maués (2005), as concepções relativas ao catolicismo popular são também comuns aos caboclos. De acordo com esse autor, os encantados, ao contrário dos santos, são seres humanos que não morreram, mas se "encantaram”, crença que tem origem europeia, ligada às concepções de príncipes e princesas encantadas que ainda sobrevivem nas histórias infantis do mundo ocidental. Mas também uma crença influenciada por concepções de origem indígena, de lugares situados "no fundo", abaixo da superfície terrestre. E ainda de origem africana, baseada em entidades como os orixás, seres que não se confundem com os espíritos dos mortos. Os encantados são pensados, destaca Maués (2005), em três contextos, onde recebem nomes diferentes: são chamados "bichos do fundo", quando se manifestam em rios, igarapés, sob forma de cobra, peixes, botos e jacarés; são chamados "oiaras", quando se manifestam sob a forma humana nos manguezais ou nas praias; são chamados "caruanas", os guias ou os cavalheiros que se manifestam nos pajés, durante as sessões xamanísticas, para praticar o bem, sobretudo para curar doenças.

A ambiguidade dos encantados, na concepção de Maués e Villacorta (1998), surge em relação ao fato de que se trata de entidades que não são pensadas como espíritos, mas como seres humanos de carne e osso, com poderes excepcionais, pois, sendo invisíveis, podem 
manifestar-se sob forma humana ou animal e ainda incorporar em pessoas comuns, apesar de manterem, durante a incorporação, sua condição de seres humanos. Não é a alma ou o espírito do encantado ou caruana que se incorpora no pajé, mas é o encantado por completo (espírito e matéria). Segundo os autores, “como isso se dá, ninguém sabe explicar, não adiante perguntar".

\section{Bichos que judiam...bichos que curam: a formação discursiva mítico/cabocla}

As famílias de agricultores da vila de Caraparu, bem como das localidades existentes ao longo das margens do rio Caraparu, são constituídas por imaginários que orientam a percepção sobre uma realidade que dá sentindo a tudo que existe no mundo relacional dessas famílias. Essas vilas foram se constituindo ao longo das margens desse rio, por isso ele representa uma das fontes de subsistência dos colonos da região: o caminho desses colonos até as áreas de roça, espaços para as lavagens de roupas das mulheres da região e para o banho e lazer dos moradores locais.

Nessas condições materiais, as narrativas que circulam entre essas famílias estão centradas nas crenças em seres "encantados" que habitam o fundo dos rios e as matas. Qualquer perturbação às entidades pode ocasionar certos males, causados por esses encantados, tais como "flechada de bicho", cujos sintomas são dores no corpo, fortes dores de cabeça e vômitos, e o "quebranto", que causa vômitos, febre etc.

Para não serem molestados por essas entidades, os moradores têm o respeito e temor ao adentrarem na mata ou no rio, espaços sagrados no imaginário desses sujeitos. Em Caraparu, Seu Manduquinha, 73 anos, exerceu um papel importante no cotidiano dos moradores locais, na medida em que, como o curador local, era o intermediador dos males causados por essas entidades. As ações maléficas provocadas pelos "bichos do fundo ou da mata", em Caraparu, são tratadas tanto por passes e benzeções quanto por ritual xamânico, em que o curador local incorpora seus guias ou caruanas. É nesse contexto ritualístico que as entidades, tendo como intermediador o pajé, curam os doentes. Nessa região, as aparições dos encantados são corriqueiras na vida diária dos colonos. Um dos encantados muito presente nos rios da região é o boto.

Dona Iracema, 73 anos, uma experiente agricultora da vila de Caraparu, disse o seguinte sobre a aparição do boto:

[01] 
cansei de ver boto tinha um boto que andava aqui no rio ele andava atrás de uma menina cansei de ver aí esse boto vinha aí se encantava aí na beira do rio [rio Caraparu]

$\mathrm{Na}$ expressão "cansei de ver boto..." reconhece-se que, para o sujeito discursivo, as entidades fazem parte de suas vivências cotidianas, pois passam boa parte de suas vidas na lida entre o rio e a roça de mandioca. Outro relato interessante sobre esse "bicho do fundo" foi de Dona Maria, 74 anos, uma agricultora antiga da vila do Lago:

Eu achei que ele queria fazer alguma coisa comigo quando eu ia chegando na beira do garapé [rio Caraparu] eu vi aquele bicho meio branco queria me puxar pro fundo eu não tinha força mais de nadar meu filho me puxou quase eu morro me deu frio, febre, dor de cabeça e dor no corpo eu fiquei com pavor de tomar banho no rio depois da roça

Nesta sequência discursiva reconhece-se que a vida diária dos colonos da região é governada por entidades que têm o controle dos espaços, de onde provém boa parte da subsistência das famílias. A relação do sujeito com as entidades está pautada no respeito e no temor às divindades que fazem parte de suas vivências, ao mesmo tempo em que se sente protegido em seu ambiente de trabalho pela divindade. Essa proteção decorre da exigência de um comportamento respeitoso nos espaços controlados pelas divindades, uma vez que, para permanecerem nesses locais sem serem molestados, os moradores precisam "pedir licença" aos encantados.

Seu José, 60 anos, um antigo agricultor da vila do Lago, concedeu uma entrevista em que narrava as aparições das entidades na região. Ele relatou que sempre que está no retiro, trabalhando com a produção da farinha de mandioca, aparece para ele uma moça na beira do córrego:

já vi a mãe do rio, a oiara meio dia ela só parece pra mim, eu chamo o pessoal para ver ela some é só eu que vejo ela, aí eu chamo os menino para ver, ela só se amostra pra mim (risos)

A narrativa do Seu José continua:

é um olho d'água que tem aí [ele faz referência ao igarapé que corta os quintais dos moradores da vila do Lago] ela é uma encantada que vive aí eu já bati foto pra ver se aparece pra mim na fotografia é a mãe do rio a mãe d'água aí eu respeito esse horário de meio dia e seis da tarde. 
No trecho “é a mãe do rio, a mãe d'água, aí eu respeito esse horário de meio dia e seis da tarde", compreende-se o funcionamento discursivo sustentado por um imaginário em que o sujeito discursivo considera a entidade como a "dona" do rio, aquela que está ali para proteger o ambiente de onde provém o sustento familiar, por isso deve respeito à entidade protetora do rio. Institui-se o respeito à propriedade alheia, o cuidado em não invadir o terreno do outro sem permissão, na medida em que o rio e a mata são territórios que, no imaginário do colono, são sagrados. A sacralidade dos lugares de mata e de rio implica, simultaneamente, a distância e o pertencimento dos colonos em relação aos espaços em que vivem. Os espaços têm donos e são controlados pelas entidades sagradas a que pertencem, ao mesmo tempo em que são espaços onde os agricultores e as agricultoras têm permissão para constituir-se como sujeito de trabalho, para prover a subsistência de suas famílias, para experienciar as condições materiais de sua existência, desde que submetido às regras estabelecidas no contato entre humanos e nãohumanos, que desconhece a existência de dicotomias ou antagonismos entre o natural e o sobrenatural, conforme Wawzyniak (2012).

O imaginário que constitui a realidade da relação entre os colonos e os encantados funciona também em bases semelhantes a que se constitui a realidade da relação maternal. $\mathrm{O}$ sujeito discursivo assimila que a "mãe do mato" e a "mãe do rio" estão ligadas ao sentido de divindade e da mãe protetora de seus filhos. Da mesma forma que esse sujeito tem respeito e, ao mesmo tempo, temor dos castigos de sua mãe por tê-la desobedecido, ele expressa esse respeito e esse temor pelas entidades.

Na sequência "ela só se amostra pra mim", reconhece-se ainda que entre os colonos constitui-se também uma hierarquia, na qual há aqueles privilegiados com os quais a relação com os encantados se estabelece de forma singular, concedendo-se a alguns o privilégio de manter contato com eles.

Em entrevista com Dona Maria (74 anos), na medida em que a conversa sobre os encantados se aprofundava, ela afirmou que:

a cacimba ${ }^{6}$ quem toma conta é a oiara

Geralmente, as cacimbas são utilizadas para lavagem de roupas e servem, também, para o banho dos moradores. A expressão "quem toma conta" reitera que a entidade tem o controle

\footnotetext{
${ }^{6}$ Espécie de olho d'água que se forma à beira do igarapé, formando pequenas piscinas naturais.
} 
desse espaço, protegendo-o, pois, para o sujeito, os locais onde vivem as entidades são sagrados. Portanto, devem respeitar e pedir autorização para usar esses espaços para lazer e trabalho.

Uma outra moradora, Dona Rita (99 anos), uma agricultora experiente da região, afirmou que:

[06]

a oiara é a mãe do garapé meio dia é hora que não pode ir na beira do garapé, criança, gente menstruada não pode porque é hora que tão fazendo linha[andando], a mãe d'água

respeito o horário de meio dia e seis da tarde, eu ralho [falar em voz alta em tom de repreensão] com as crianças porque não gosto que eles vão pro garapé meio dia e seis da tarde. Já morreu gente nesse garapé, de tarde também não gosto

As sequências discursivas destacadas indicam que o rio e a mata, espaços de onde provém boa parte do sustento familiar, têm donos que, no nível simbólico, produzem uma realidade regida de acordo com as leis dos encantados, considerados os guardiões desses espaços. E como os agricultores e as agricultoras necessitam adentrar na mata, para a lida com o trabalho na roça, e no rio, para a pesca e para chegar até às áreas de roça de mandioca, o respeito aos horários sagrados são formas de submeter-se ao controle desses espaços.

Esse funcionamento discursivo resulta em uma formação discursiva e uma formação ideológica denominada nesta pesquisa de mítico/cabocla. Essa formação discursiva e ideológica é sustentada por um imaginário acessado pelas práticas discursivas, no sentido de produzir uma realidade em que a crença no mito encontra força e não se dissipa, levando os mais jovens a acreditarem nos mais antigos, quando ordenam que respeitem os horários sagrados na vivência dos espaços dos encantados. Por exemplo, os dizeres de Dona Rita, "das onze horas até meio dia pode", implica uma forma de controle dos encantados sobre a vida diária dos moradores.

Seu Walgner (60 anos), um colono caçador antigo do lugar, afirmou já ter ficado "mundiado" pelo curupira. Ele diz:

[08]

o curupira judiou de mim quando eu armava minha espingarda na mata

Disse ainda que, para evitar ser mundiado novamente, teve que "jogar água benta na espingarda". Ele informou que muitos caçadores da região 
Quando o sujeito discursivo se refere aos males causados por um encantado, é comum evocar a expressão "judiar", que denota a forma como esse sujeito é afetado por uma doença espiritual, entendida como punição pelo desrespeito às regras da natureza, pois o sujeito enxerga o espaço da mata e do rio como um ambiente que divide com as entidades e que possui regras ditadas por esses seres. A ação relatada de "jogar água benta” denota a busca de proteção contra os males causados por esses seres, um rito do catolicismo popular que esses colonos acionam para proteger seus instrumentos de trabalho e como forma de proteção contra as doenças espirituais lançadas pelo encantado. No dizer de Seu Manduquinha, os encantados do fundo estão sumindo:

[10]

Eles tão sumindo também porque jogam água benta neles

E porque os encantados do fundo somem quando "jogam água benta neles"? O sujeito discursivo justifica a ausência da entidade no rio por um rito do catolicismo popular. Para ele, o encantado sente que sua morada está sendo invadida por um outro tipo de ritual que, historicamente, também faz parte da sua formação religiosa. Entende-se, então, que o imaginário continua a sustentar a crença nas regras que se estabelecem na relação entre humanos e não-humanos, pois o colono justifica, em suas práticas discursivas, a ausência e não a inexistência das entidades que habitam os lugares sagrados e os controlam.

As sequências discursivas revelam que as práticas de sobrevivência dos colonos são reguladas por um sistema de crenças, compreendido como efeito do assujeitamento ideológico à formação discursiva mítico/cabocla, na qual a "mãe da mata" e a "mãe do rio" são consideradas protetoras dos lugares sagrados de onde provém o sustento familiar, levando o sujeito a pedir licença para a "mãe", para que as doenças espirituais não o atinjam. Desse modo, assume uma atitude de respeito às regras impostas pelo mundo mítico que habita ao mesmo tempo em que sente-se amparado/protegido no seu cotidiano. Entende-se que há materialidades discursivas que filiam a ideia do trabalho, do lazer e da religiosidade à crença em mundo mítico, pois o sujeito discursivo fala de um lugar social inscrito na estrutura de sua formação social e econômica baseada em práticas religiosas caboclas e em práticas de subsistência familiar em que os espaços da mata e do rio são lugares onde passam boa parte do dia na lida diária.

A expressão "dê licença" ou "pedir licença" circula com muita frequência nas narrativas do sujeito. No momento em que o sujeito diz "minha vizinha dê licença pra mim entrar no seu 
garapé”, o efeito de sentidos implicado nesse dizer revela a relação de poder e subserviência entre o sujeito e a entidade. Ou seja, a "mãe" é a dona do espaço e se o colono adentrar sem autorização sofre sanções. Por sua vez, o vocativo "minha vizinha" denota "proximidade" em relação aos encantados, uma relação marcada pela solidariedade e ajuda mútua de um bom vizinho, pois o termo "vizinho", em muitas áreas da Amazônia, denota ajuda mútua, respeito e solidariedade entre indivíduos que residem muito próximos uns dos outros. Os colonos de Caraparu, em momentos difíceis, sempre podem contar uns com os outros pela proximidade que se estabelece entre eles, tanto geograficamente quanto socialmente. E isto se estende às relações com os não-humanos, o que gerará, nessa relação, o sentimento de respeito e reciprocidade. E, assim, eles poderão trabalhar ou praticar o lazer com segurança, entendendo que, respeitando o local sagrado, nenhum mal se abaterá sobre eles e, ainda, terão a proteção do encantado como retribuição pelo respeito devido.

Diante do exposto, entende-se que as sequências discursivas demonstram que o sistema de crença do colono é a materialização ideológica do imaginário, constituindo uma realidade segundo o qual os meios de subsistência, ou seja, o rio e a mata, têm um dono/dona, entidades sagradas que o colono teme e a que deve respeito, por acreditar que suas reais condições de existência, isto é, aquele modo de produção marcado por uma economia voltada para subsistência com poucos excedentes comercializados fora da região é governado por entidades sagradas. Então a ideologia que carrega esse imaginário se materializa em práticas discursivas a que o sujeito se filia para estabelecer um tipo de relação com os seres encantados, caracterizada pelo respeito, pelo temor, pela proteção e pela reciprocidade, pois o contrário implicaria em quebra das regras que resultariam em sanções.

\section{Notas reflexivas}

As análises das sequências discursivas se basearam no postulado de que o imaginário funciona através das práticas discursivas. Em conformidade com Pêcheux (1975, p.160), partiuse da premissa de que é a ideologia que fornece as evidências que fazem com que uma palavra ou um enunciado assumam um sentido material. No escopo específico dos enunciados investigados nesta pesquisa, são as práticas discursivas de agricultores e agricultoras que sustentam a crença em um mundo invisível. São elas que estabelecem e garantem um conjunto de regras que rege a convivência entre humanos e não-humanos, baseada na hierarquia, na obediência e na reciprocidade. Com base na análise do corpus, reconheceu-se que o 
funcionamento discursivo do imaginário mítico/caboclo ainda se movimenta com muita força entre os colonos idosos da vila de Caraparu.

Então, a relação do sujeito com as entidades pode ser vista como uma ilusão representada pelo trabalho da linguagem, que o inscreve, ideologicamente, em um conjunto de sentidos que foram constituídos nas e pelas práticas discursivas, historicamente, em sua vida diária de roça, pesca e caça.

O caso em estudo remete às condições sócio-históricas do agricultor e da agricultora tradicional da vila de Caraparu e suas redondezas, que vivem do trabalho na roça às margens do rio e nas matas, onde sua singularidade proporciona a produção de uma forma de imaginário que projeta sobre o real a existência de "bichos" sobrenaturais que são os "donos" dos lugares de onde provém o sustento da família e, portanto, onde circula o colono em sua vida diária.

Entende-se que esse imaginário mítico é construído a partir de uma ideologia que assujeita a uma formação discursiva, aqui denominada mítico/cabocla, que leva o sujeito a formular narrativas que, ao circularem, reafirmam a crença em seres sobrenaturais. A pesquisa também permitiu reconhecer que a formação discursiva mítica/cabocla, aqui descrita em algumas de suas regularidades, se confronta com as transformações que vão se impondo ao modo de vida dos colonos na contemporaneidade, o que permite investigar o quanto essa formação discursiva resiste ou se transforma entre os colonos mais jovens da região. Mas essa discussão deve continuar em outros escritos.

\section{REFERÊNCIAS}

ALTHUSSER, Louis. Ideologia e Aparelhos Ideológicos de Estado. Tradução de Joaquim José de Moura Ramos. Biblioteca Universal. Editorial Presença/Martins Fontes,1970.

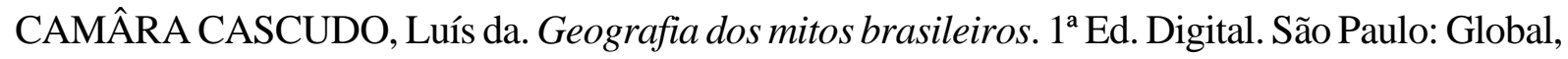
2012.

DESCOLA, Phillippe. In the society of nature: a native ecology in Amazônia. Cambridge: Cambridge University Press, 1994.

DORNELLES, Elizabeth Fontoura. O discurso do M.S.T: um acontecimento na estrutura agrária brasileira. In: INDURSKY, Freda; FERREIRA, Maria Cristina Leandro (Orgs). Os múltiplos territórios da Análise do Discurso. Coleção Ensaios, Vol.12. Porto Alegre, RS: Ed. Sagra Luzatto,1999, p. 149-172.

ELIADE, Micea. Mito e Realidade. Tradução de Pola Civelli. São Paulo: Perspectiva, 2002.

ELIADE, Micea. Imagens e Simbolismo: ensaio sobre o simbolismo mágico-religioso. Tradução de Sônia Cristina Tamer. São Paulo: Martins Fontes, 2001. 
FERNANDES, Carolina. O imaginário de veja sobre os lulas presidenciáveis. Universidade do Rio Grande do Sul. Dissertação de Mestrado. Programa de Pós- Graduação em Letras, 2008.

MAUÉS, Raymundo Heraldo. Um aspecto da diversidade cultural do caboclo amazônico: a religião. Estudos Avançados. Vol.19 no 53. Dossiê Amazônia Brasileira: São Paulo, Janeiro/abril, 2005. 1995. . Uma outra invenção da Amazônia: religiões, histórias e identidades. Belém: Ed. Cejup,

MAUÉS, Raymundo Heraldo; VILLA CORTA, Gisela Macambira. Pajelança e encantaria amazônica. Trabalho apresentado no Simpósio de Pesquisa Conjunta "As religiões afrobrasileiras". (PQ01), nas VIII Jornadas sobre Alternativas Religiosas na América Latina, a realizar-se em São Paulo/SP, de 22 a 25 de setembro de 1998.

NOBRE, Mariléia da Silveira. Entre o "trabalho na roça" e a "venda na beira": um estudo da dinâmica no modo de vida das famílias de Caraparu-Pará. Dissertação de Mestrado. Programa de Ciências Sociais/Antropologia, Universidade Federal do Pará, 2007.

NOBRE, Mariléia da Silveira. O turismo e a questão ambiental na Vila de Caraparu - Santa Izabel do Pará: perspectivas para o uso e gerenciamento do ambiente sociocultural. Trabalho de Conclusão de Curso. Universidade Federal do Pará, 2004.

ORLANDI, E.P. Análise do discurso: Princípios e procedimentos. Campinas: Pontes, 2012.

PÊCHEUX, Michel. Semântica e discurso: uma crítica à afirmação do óbvio. Tradução de Eni P. Orlandi. 2. ed. Campinas, SP: Unicamp, 1995 [1975].

WAWZYNIAK, Joao Valentim. Humanos e não-humanos no universo transformacional dos ribeirinhos do Rio Tapajós-Pará. Dossiê-Amazônia: Sociedade e Natureza. Mediações, Londrina, v.17 n. 1, p.17-32, jan/jun.2012.

Recebido em 14/05/2020. Aceito em 17/08/2020. 